\title{
Determination of the Possible Causes of Cracks in Pins of Quick Operating Valves in Hydroelectric Power Plant
}

\author{
Patrik Šarga ${ }^{1, a^{*}}$, František Trebuňa ${ }^{1, b}$, František Šimčák ${ }^{1, c}$ \\ and Jozef Bocko ${ }^{1, d}$, \\ ${ }^{1}$ Department of Applied Mechanics and Mechatronics, Technical University of Košice, Faculty of \\ Mechanical Engineering, Košice, Slovakia

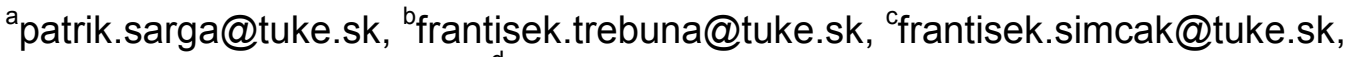 \\ jozef.bocko@tuke.sk
}

Keywords: Hydroelectric power plant, residual stresses, hole-drilling method, FEM

\begin{abstract}
During the revision of the individual parts of a hydroelectric power plant the cracks in the pins of quick operating and revision flap valves of Francis turbine were found. Our department has been approached with a request to investigate the causes of these cracks. This paper deals with the complex analysis of influential factors, especially the measurements of residual stresses by holedrilling method, in order to reveal the factors causing the cracks in the pins.
\end{abstract}

\section{Introduction}

The hydroelectric power plant serves for the production of electric energy. It is a technological unit that converts the potential energy of water to the electric energy. The hydroelectric power plant consists of dam and powerhouse with turbines and generators for production of electric energy. The hydroelectric power plants work on different principles and one of them is based on using of Francis turbine (Fig. 1).

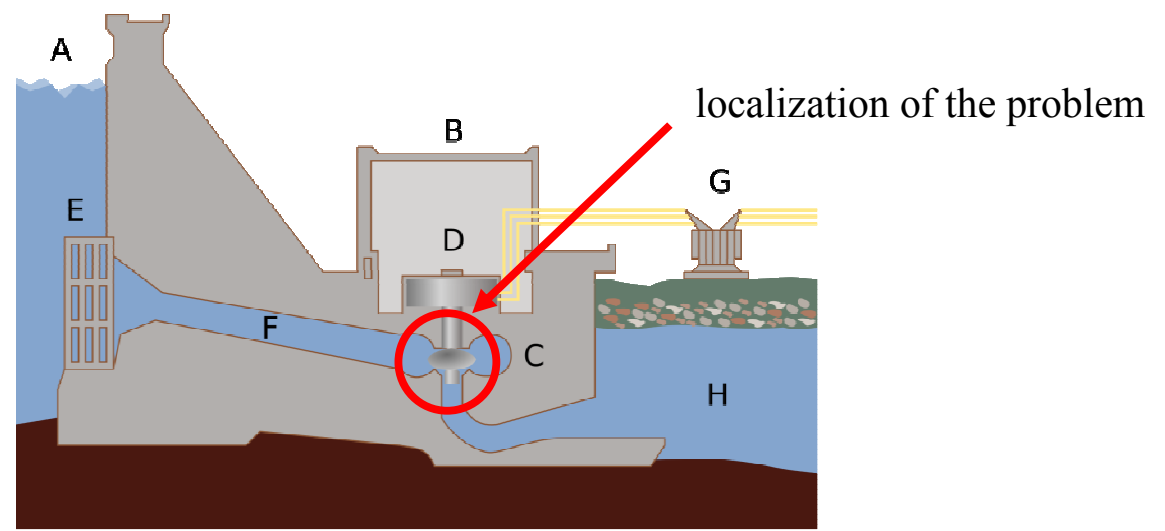

Fig. 1 Scheme of hydroelectric power plant

$\mathrm{A}$ - reservoir, $\mathrm{B}$ - powerhouse, $\mathrm{C}$ - Francis turbine, $\mathrm{D}$ - generator, $\mathrm{E}$ - intake, $\mathrm{F}$ - penstock, $\mathrm{G}$ - long distance power lines, $\mathrm{H}$ - river

One of many important parts of such system is a quick operating flap valve and revision flap valve positioned before inlet of water to the turbine spiral, Fig.2 [1].

Revision flap valve serves as doubled device for closing water flow in the inlet piping for the revision and reparation works. It closes the water flow to the turbine also in the case of failure of the operation valve. Revision flap valve consists of welded two-part case in which is positioned in two bronze bearings the lens-shaped closing body. The flap valve is controlled by two servomotors.

Quick operating flap valve closes the inlet piping to the turbine also in case of full water flow when the cross-section area of distribution pipe is fully opened. It is designed similarly as the revision flap valve. Opening and closing of valve during start and finish of the work of generator is automatic and it is accomplished under the same pressure in pipe before and after flap valve. 


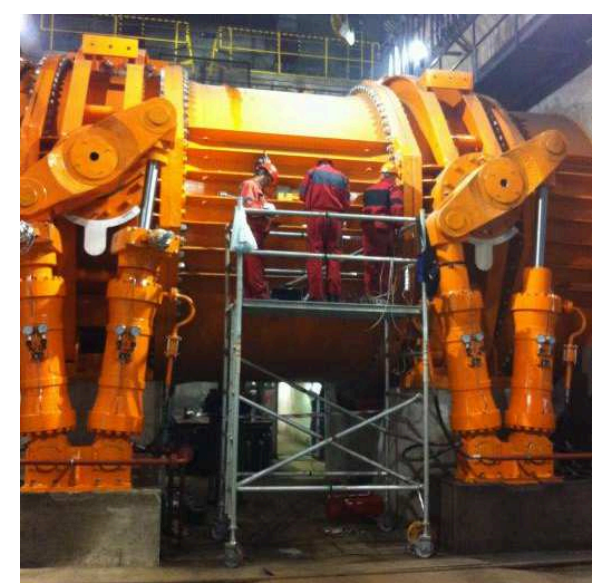

Fig.2 View to the revision flap valve and quick operating flap valve of inlet piping

Quick operating valve consists of lens-shaped closing body which is positioned in case of flap valve by driving (Fig. 3) and driven pins (Fig.4).

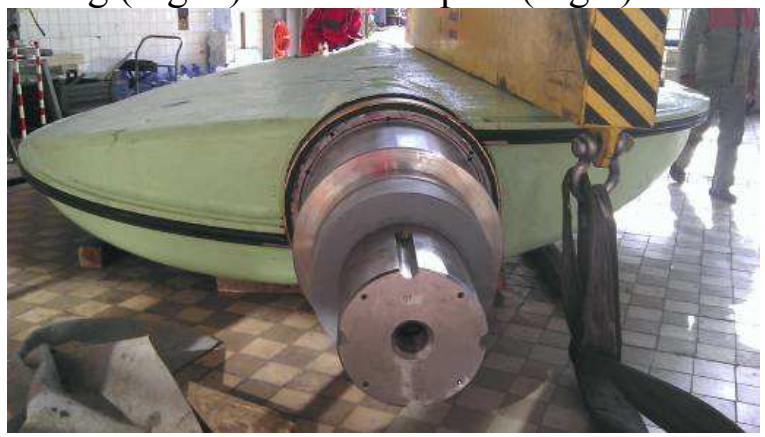

Fig.3 Driving pin of lens-shaped flap valve

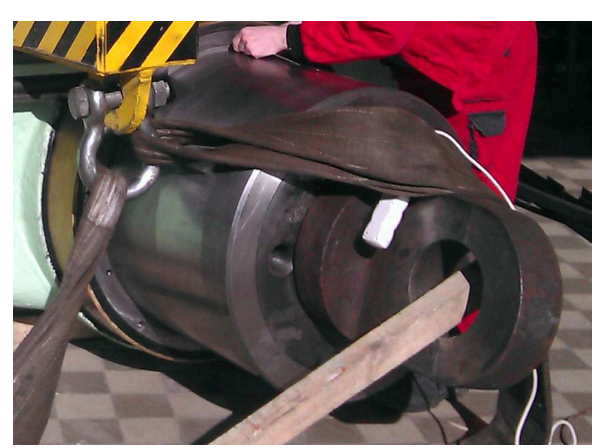

Fig.4 Driven pin of flap valve

The pins are made of steel 13123.1. They were produced as forged pieces whose function surfaces after machining and before welding had diameters $744 \mathrm{~mm}$ and in the locations of contacts were used radiuses $5 \mathrm{~mm}$. On the function surfaces of the pins were applied welds thick $3 \mathrm{~mm}$ after machining. Accordingly, the resulting diameter of function surfaces of pins was $750 \mathrm{~mm}$. After welding the tempering at the temperature $300^{\circ} \mathrm{C}$ during 4 hours has been accomplished [2].

During disassembling of revision and quick operating flap valves the cracks have been detected in their pins. The cracks were located on the surfaces of driving as well as driven pin and they were oriented in axial directions of pins (Fig. 5). Detailed description of the dimensions and orientations of the cracks can be found in [2].

In the following chapter is described the treatment that leads to identification of possible causes of the cracks in pins.

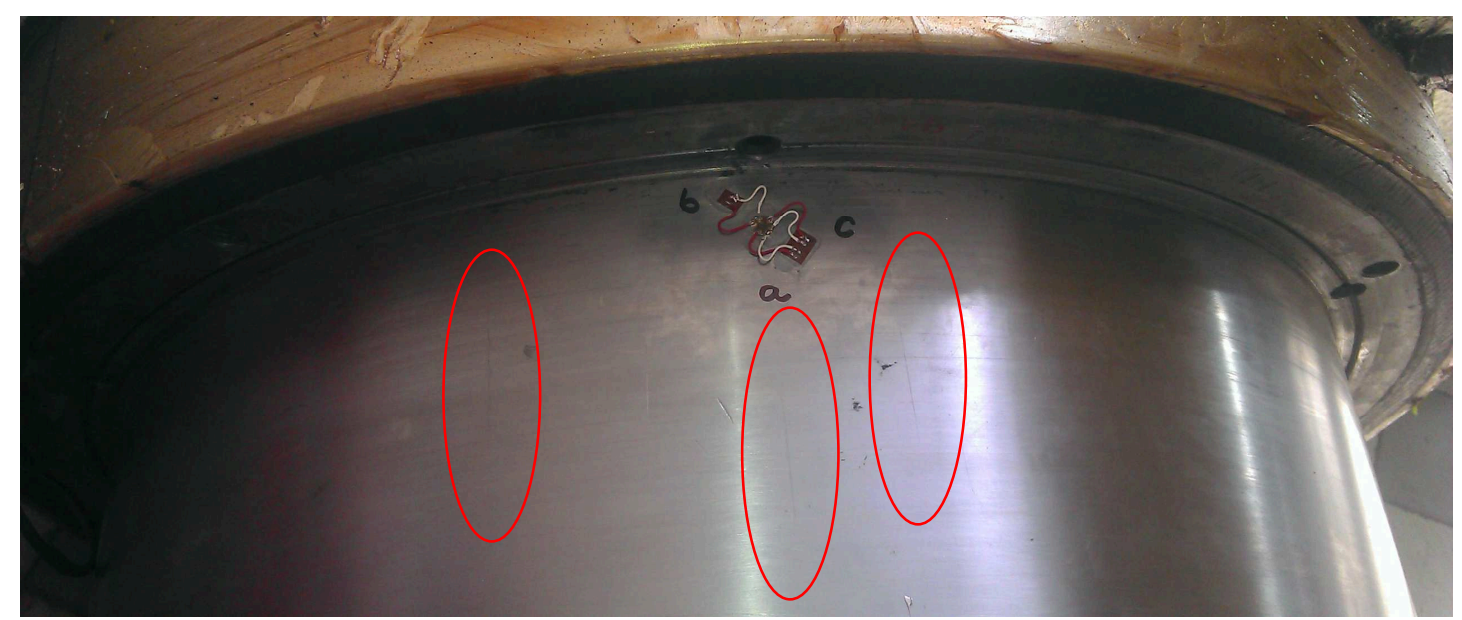

Fig. 5 Driven pin with cracks 


\section{Stress analysis of pins by the finite element method for operational loading of flap valves}

The flap valves are loaded during their operation by a hydrostatic pressure of water column $60 \mathrm{~m}$ high that causes bending and torsion loading of pins. The bending moment acts on driving and driven pin, the torsion is transferred only by driving pin, through which the opening and closing of flap valve is realized by hydraulic cylinders.

The principal normal stresses on driving as well as driven pins of flap valves have been determined by the finite element method.

In Fig. 6 and Fig.7, respectively are given fields of equivalent stresses caused by operation loading on driving and driven pins.

Nominal values of stresses due to torsion reach maximum value $18 \mathrm{MPa}$ and nominal stresses resulting from bending are approximately $30 \mathrm{MPa}$. The shape coefficient determining stress concentration in locations of contact surfaces of driving as well as driven pin reach values at the range $3.5-4.0$ so that maximum stresses due to bending with respect to the concentrator slightly exceed $100 \mathrm{MPa}$.

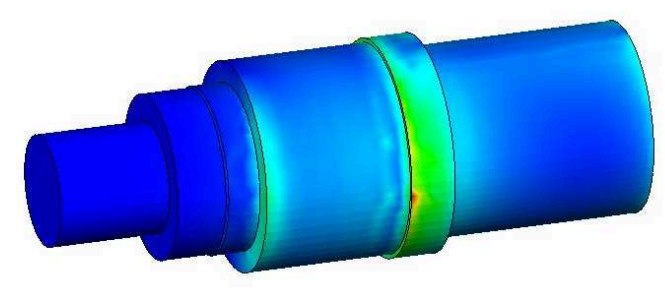

Fig.6 Field of equivalent stresses on driving pin for operating loading

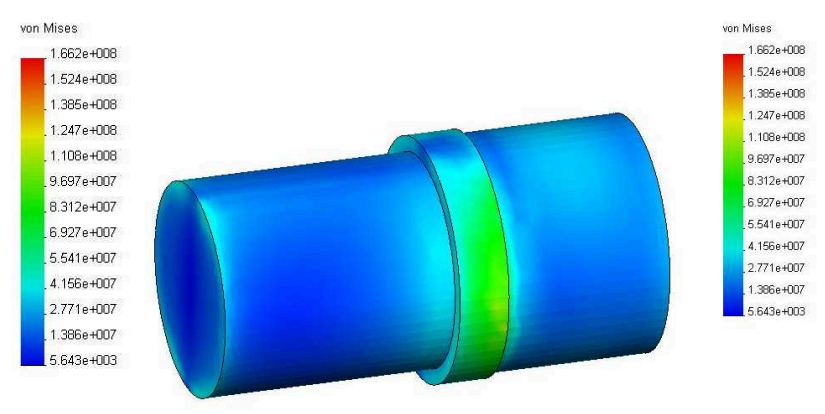

Fig.7 Field of equivalent stresses on driven pin for operating loading

The torsion moment is transmitted only through driving pin, i.e. the torsion moment in driven pin results only from passive friction forces.

Because the maximal values of stresses due to torsion do not exceed on function surface of driving pin $18 \mathrm{MPa}$, it can be stated that shear stresses do not cause cracks in pins.

It is interesting that all cracks are oriented in axial direction. The loading of pins by bending moment results to normal stresses in axial direction. Conclusion is that the cracks due to variable bending should be oriented perpendicular to the pin axes, i.e. the cracks on both pins cannot be caused by operation bending loading. Because the submerged arc welding on function surfaces of driving and driven pins is accomplished along spiral, it cannot be supposed that bad welding parameters can lead to cracks with different than circumferential direction.

Given simplification documents that stresses due to operation loading (by hydrostatic pressure or resulting from hydraulic cylinders) cannot be main reason of identified cracks. The reasons of crack creation are residual stresses due to using of inappropriate manufacturing process or unsuitable welding and tempering.

\section{Determination of residual stresses on the surface of pins by the hole-drilling method}

Described facts lead the authors to quantification of residual stress levels in locations with the highest concentration of cracks. In these locations on driving and driven pins were applied straingages for the hole-drilling method. Distances between centers of strain-gages were the smallest possible allowing realization of hole-drilling from the technological point of view, but on the other side they allow to quantify influence of stresses to possible crack initiation.

The measurement system MTS 3000 made by SINT has been used for the measurement of residual stresses by the hole-drilling method. Released deformations have been measured by straingages 1RY61-1.5/120S made by HBM and apparatus Spider 8-30. Measurement chain is shown in 
Fig.8 [3]. Together 5 measurements were realized. Each measurement was performed by creating a hole with a diameter of $1.6 \mathrm{~mm}$ up to total depth of $2 \mathrm{~mm}$, reached in 20 steps.

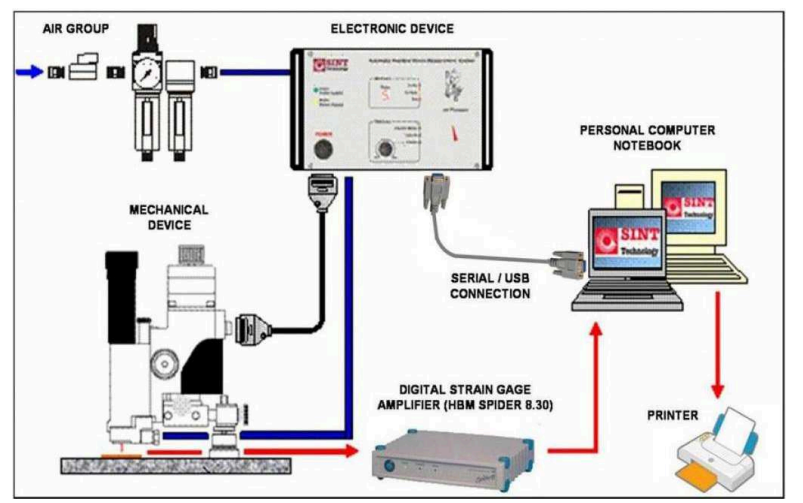

Fig.8 Measurement chain for the measurement of residual stresses Fig.9

The positions of strain-gages 1 and 2 on a driving pin as well as their orientations are given in

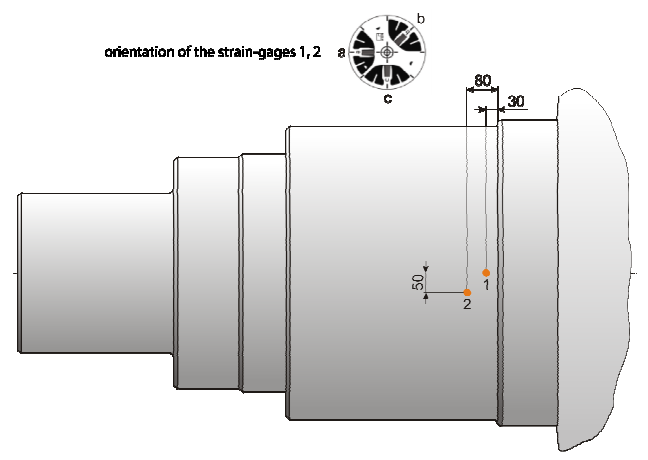

Fig.9 Position and orientation of straingages on driving pin

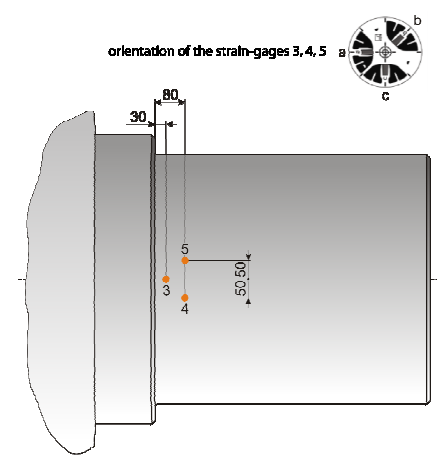

Fig.10 Position and orientation of straingages on driven pin

Three strain-gages have been applied on the driven pin because of higher crack concentration at three locations. The positions and orientations of strain-gages are given in Fig.10.

In Fig. 11 is shown measurement system MTS 3000 during hole-drilling at the location of straingage No. 1 (Fig. 12).

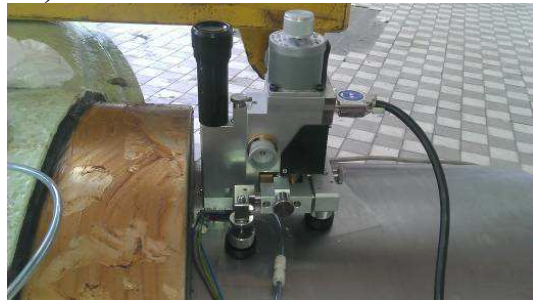

Fig.11 Measurement system MTS 3000 during hole-drilling at the location of strain-gage No. 1

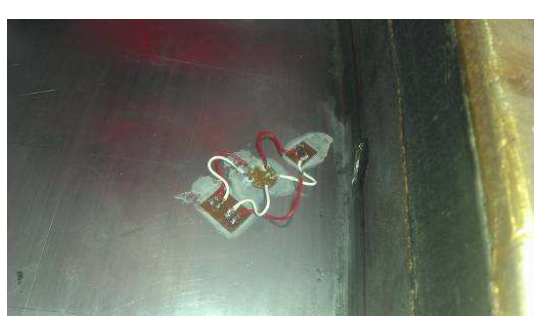

Fig.12 Strain-gage No. 1 applied on driving pin

In Fig. 13 is a photograph of hole-drilling equipment during drilling. The view to driving pin after drilling of all three holes is given in Fig. 14. 


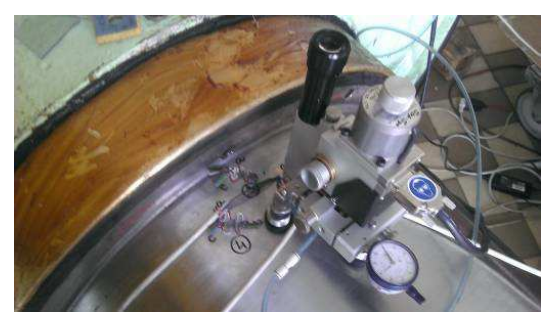

Fig.13 Measurement system MTS 3000 during hole drilling at the position of strain-gage No. 3

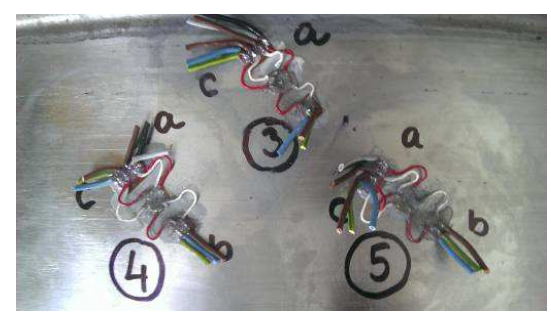

Fig.14 Driven pin after drilling

Strain-gage rosettes have been always oriented in such a way that sensor $a$ was in axial direction and sensor $c$ in circumferential direction.

After measurement and evaluation by program products the residual stresses in individual locations of measurement were determined according to ASTM E837-08, Integral as well as Kockelman method [4].

In Fig. 15 is given example of results according to ASTM for non-uniform stresses.
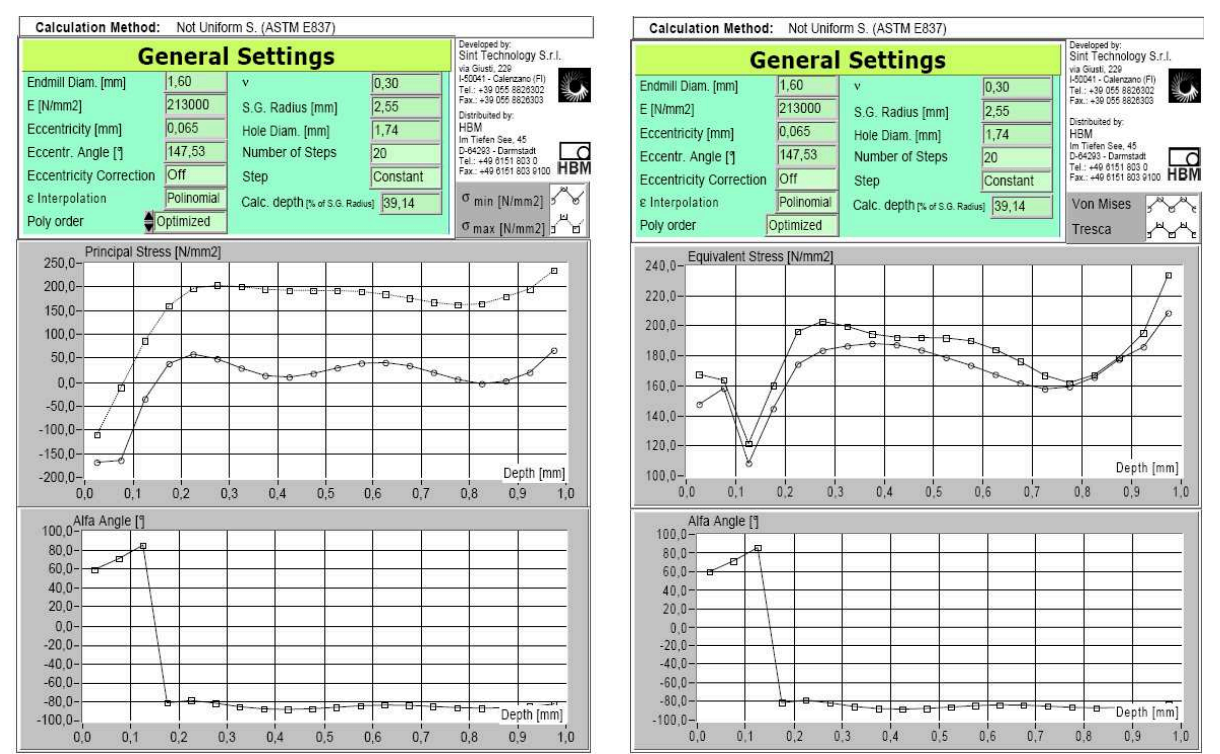

Fig.15 Example of measurement results according to non-uniform ASTM method

In Tab. 1 are given results of measurements according to ASTM (for uniform stresses), principal stresses $\sigma_{\max }$ and $\sigma_{\min }$ and declination angle $\varphi$ of maximum stress with respect to axis of a pin.

It has been found out that in all locations ( 1 to 5 ) the maximal normal stresses are always in circumferential direction, i.e. they are perpendicular to the cracks. Further very important fact is that in surface layer in depth of $0.2 \mathrm{~mm}$ there is a compression stress, but with increasing of hole depth the stresses became positive and they reach approximately $200 \mathrm{MPa}$ with equivalent stresses up to $250 \mathrm{MPa}[5]$.

Tab.1 Results of measurements according to ASTM

\begin{tabular}{|c|c|c|c|c|}
\hline & Location & $\sigma_{\max }[\mathrm{MPa}]$ & $\sigma_{\min }[\mathrm{MPa}]$ & $\varphi\left[^{\circ}\right]$ \\
\hline \multirow{2}{*}{ Driving pin } & 1 & 124,58 & $-4,83$ & $-86,95$ \\
\cline { 2 - 5 } & 2 & 135,65 & $-5,44$ & $-87,59$ \\
\hline \multirow{3}{*}{ Driven pin } & 3 & 157,20 & $-5,98$ & $-87,97$ \\
\cline { 2 - 5 } & 4 & 152,12 & $-5,29$ & $-87,47$ \\
\cline { 2 - 5 } & 5 & 159,12 & $-6,01$ & $-88,13$ \\
\hline
\end{tabular}


If we consider that minimal yield point of material is $\mathrm{R}_{\mathrm{emin}}=265 \mathrm{MPa}$, the residual stresses lie almost on the yield point. Therefore, it can be stated that on the tip of cracks are elasto-plastic deformations. It means that crack initiation can occur and without decreasing of residual stresses the cracks will be initiated and spread also in the future.

\section{Conclusions}

Orientation and length of cracks document that they can be initiated only by residual stresses. The residual stresses were not removed probably due to low temperature of tempering [2]. At the same time, the duration of tempering [2] was inappropriate. Amount and orientation of tensile residual stresses correspond with fact that residual stresses result from welding.

Driven and driving pins of flap valves should fulfill their functions without time limits also in the presence of actual cracks under condition that residual stresses do not exceed approximately $50 \mathrm{MPa}$.

The reparation should consist of removing of the cracks by turning and making of new surface layer by welding. The pins then have to be tempered under suitable conditions before final turning to definitive dimensions. Actual levels of residual stresses do not guarantee that new cracks will not be initiated or the existed cracks will not grow. The authors supposed that removing of cracks by turning, creation of new surface layer by welding and tempering under prescribed conditions is the only possible method for pins reparation that ensure their safe operation without time limits.

\section{Acknowledgements}

The work has been accomplished under the research projects VEGA 1/0937/12, VEGA 1/0393/14 and project FGV/2013/9.

\section{References}

[1] Trebuňa F. et al., Expertíza tabúl' provizórneho hradenia vtokov TG1 a TG2 vo VE Ružín I, TU Košice, 2004.

[2] Istenes, I.: Vyhodnotenie trhlín na čapoch klapkových uzáveroch z TJ Ružín. ROEZ Stress Analysis. Bratislava, 2012

[3] Trebuňa, F., Šimčák, F.: Kvantifikácia zvyškových napätí tenzometrickými metódami. Prešov, Grafotlač 2005

[4] ASTM E837-08 Standard Test Method for Determining Residual Stresses by the Hole-Drilling Strain-Gage Method, USA, 2009.

[5] Trebuňa F. et al., Výpočet zbytkovej životnosti klapiek pre sústrojenstvo TG1 a TG2 PVE Ružín, 2012. 